\title{
A metodologia ativa como auxiliar no ensino de design a distância
}

The active methodology as an aid in the teaching of distance design

\author{
CAMARGO, Larissa Siqueira. Doutoranda; Anhembi Morumbi; Unicesumar \\ larissa.camargo@unicesumar.edu.br \\ LEVINTON, Sabrina Giselle; Doutoranda; Unicesumar \\ sabrina.levinton@unicesumar.edu.br
}

\section{Resumo}

A educação a distância é uma realidade atual que surgiu com um objetivo inicial e acabou por atender outras demandas, inclusive a do novo perfil de estudantes, da atual geração que já não encontrava na educação tradicional um estímulo para a busca do conhecimento. Paralelo a isso, e também no mesmo contexto, surgem as metodologias ativas aplicadas ao processo ensinoaprendizagem. E nessa realidade passam a se inserir os cursos superiores de tecnologia em design. Desse modo, o objetivo do presente relato é de apresentar uma experiência de atividade aplicada a um curso superior de tecnologia em design de interiores, na modalidade a distância, utilizandose da ferramenta de metodologia ativa Aprendizagem Baseada em Problemas - ABP. Assim, a experiência indicou que o uso das metodologias ativas pode ser um grande auxiliar na busca de qualidade da prática de ensino de design EAD.

Palavras Chave: aprendizagem baseada em problemas; cst em design de interiores; educação a distância.

\begin{abstract}
Distance education is a current reality that emerged with an initial objective and eventually met other demands, including that of the new student profile, of the current generation that no longer found in traditional education a stimulus for the search of knowledge. Parallel to this, and also in the same context, are the active methodologies applied to the teaching-learning process. And in this reality they begin to insert the superior courses of technology in design. Thus, the objective of the present report is to present an experience of applied activity to a superior course of technology in interior design, in the distance modality, using the tool of active methodology Problem-Based Learning - ABP. Thus, the experience indicated that the use of the active methodologies can be a great aid in the search for quality of the teaching practice of EAD design.
\end{abstract}

Keywords: problem-based learning; cst in interior design; distance learning. 


\section{O ensino de design, os cursos superiores de tecnologia e a educação a distância}

Assim como na Bauhaus, o ensino de design no Brasil originou-se a partir do que profissionais da área de arquitetura e das artes plásticas buscaram uma identidade as suas produções, visando a industrialização e assim, o acesso as suas peças, sendo que esses primórdios basearam-se na produção contemporânea, tendo como inspiração, em especial, o Funcionalismo (LANDIM, 2010).

Ainda assim, segundo Landim (2010), na década de 1960 os cursos de design apareciam de forma tímida e poucos expressivos, já que os egressos desses cursos encontravam ainda dificuldades de serem aceitos no mercado nacional, que estava em fase de consumo americanizado e de nomes internacionais. Foi na década de 1970 que o governo passou por um processo de investimento tecnológico, em contrapartida a diminuição de investimento nas áreas artísticas, o que impactou diretamente nos cursos de formação em artes visuais e plásticas, forçando-os a mudarem para cursos de design de forma imediata.

Para entendermos melhor o crescimento dos cursos de design no Brasil, podemos comparar os números atuais com os encontrados em 2016 (um ano atrás), onde estavam cadastrados 687 cursos de graduação em design, considerando os 870 atuais, tivemos um aumento de mais cerca de 15\%. Destes, em 2016, 7 eram ofertados na modalidade à distância, e assim, em um ano esse número mais do que dobrou, alcançando os 16 cursos (e-mec).

Paralelo ao movimento crescente dos cursos de design, surgem no Brasil os cursos superiores de tecnologia (CST), com o parecer 1.060 de 1973, do Conselho Federal de Educação (CFE), e assim, muitos cursos superiores de design passam a ter a formação tecnóloga, e para compreender essa movimentação, precisamos compreender o que são os cursos tecnólogos.

A cada nova reformulação da LDB, os cursos tecnológicos foram ganhando forma e força, mas foi somente na década de 1990 que passaram a ser ofertados de forma mais ampla (TAKAHASHI, 2010). A difusão dessa formação se deu através de cursos na área de computação, sendo que a oferta começou a se diversificar a partir de 1988, quando foi autorizado o primeiro CST em Hotelaria. E assim, segundo Takahashi (2010), com o crescimento e diversificação, em 1994 a Lei no 8.948 instituiu Sistema Nacional de Educação Tecnológica, mas, foi em 1996, através da LDB no 9.394/96, e com o Decreto Federal no 2.208/97 que os CST ganharam forma e uma nova dimensão no pai.

Com isso, novos pareceres surgiram a fim de organizar a modalidade, e o parecer CNE/CES no 436/2001, aprovado pela Câmara de Educação Superior do Conselho Nacional de Educação, definiu cursos superiores de tecnologia como:

Cursos de graduação com características especiais, bem distintos dos tradicionais e cujo acesso se fará por processo seletivo, a juízo das instituições que os ministrem. Obedecerão a diretrizes curriculares nacionais a serem aprovadas pelo Conselho Nacional de Educação (BRASIL, 2001).

Sendo as características especiais e distintas o foco, já que a formação tecnológica estabelece um campo de trabalho e atuação bem definidos, a rapidez, sendo que os cursos dessa modalidade funcionam com uma carga horária reduzida, durando entre dois ou três anos, a inserção no mercado de trabalho, considerando que a oferta desses cursos deve atender a 
demandas específicas, pontuais e locais, e a metodologia, que deve abranger técnicas, ferramentas e estratégias práticas, voltadas no aprender na prática (TAKAHASHI, 2010).

Esse perfil de atender uma demanda de mão de obra prática de mercado aparece em diferentes pontos das resoluções relacionadas, como na Resolução do Parecer no 29/2002, no art. 6o, que define:

O do Projeto de Resolução a organização curricular dos cursos superiores de tecnologia deverá contemplar o desenvolvimento de competências profissionais e será formulada em consonância com o perfil profissional de conclusão do curso, o qual define a identidade do mesmo e caracteriza o compromisso ético da instituição com os seus alunos e a sociedade.

No §10 encontramos: "a organização curricular compreenderá as competências profissionais tecnológicas, gerais e específicas, incluindo os fundamentos científicos e humanísticos necessários ao desempenho profissional do graduado em tecnologia", e no Parecer no $29 / 2002$,

o objetivo é o de capacitar o estudante para o desenvolvimento de competências profissionais que se traduzam na aplicação, no desenvolvimento (pesquisa aplicada e inovação tecnológica) e na difusão de tecnologias, na gestão de processos de produção de bens e serviços e na criação de condições para articular, mobilizar e colocar em ação conhecimentos, habilidades, valores e atitudes para responder, de forma original e criativa, com eficiência e eficácia, aos desafios e requerimentos do mundo do trabalho

Assim, para Takahashi (2010), os currículos dos CSTs devem ser flexíveis, sendo uma das maneiras de flexibilizar a modularização, organizada de forma sistêmica, o que permite a entrada e saída de aluno em diferentes momentos, e ainda, a possibilidade de certificações parciais; interdisciplinaridade, a fim de evitar a segmentação de conteúdos, considerando a formação direcionada, essencial prevenirem a falta de foco e direcionamento; contextualização, através do relacionamento do conteúdo com a prática "privilegiando metodologias que integrem a vivência e a prática profissional" (TAKAHASHI, 2010); e atualização permanente, considerando que os CSTs devem atender a uma demanda imediata do mercado, precisa estar atualizado as peculiaridades locais e temporais.

O parecer 29/2002 ainda apresenta a necessidade da realização de atividades paralelas ao curso, já no mercado, avaliando competências desenvolvidas na prática, relacionadas à formação, levando assim ao aluno, durante o curto período de tempo do curso, a já experienciar o mercado onde deverá ser inserido após a formação (TAKAHASHI, 2010).

Buscando estabelecer alguns padrões mínimos a serem atendidos pelas IES na oferta de CST, o MEC criou o catálogo de cursos tecnológicos, que apresenta uma apresentação geral do curso, explicando possíveis atuações do profissional formado no curso, carga horária mínima e infraestrutura recomendada. O catálogo apresenta uma descrição sucinta sobre o profissional que o curso deve formar, carga horária mínima e estrutura recomendada. Em 2014 o catálogo passou por uma reestruturação, onde uma consulta aberta pública foi disponibilizada para que alunos, professores, especialistas, pesquisadores, instituições de ensino superior, entidades de 
representação profissional, dentre outros, pudessem fazer sugestões quanto a novas diretrizes. 0 resultado ainda não foi publicado, assim, o último catálogo disponível data de 2010.

Desta maneira, compreendemos a relação da formação em design com os princípios da graduação tecnológica, já que o perfil da prática atende às demandas em comum. Além disso, quando a formação em design passou a ser mais direcionada, com habilitações específicas, como interiores, produto, gráfico, moda, etc., o grau de tecnólogo passe a atender plenamente a esse caráter.

Dentro das mudanças e evolução da educação nacional, a educação a distância (EAD) surgiu para oferecer a possibilidade de formação superior aos que, até então, não tinham acesso a modalidade de ensino presencial, em especial pela não existência de instituições em sua localidade ou proximidade. Desde a publicação da Lei no 9.394, de 20 de dezembro de 1996, que estabeleceu as novas Diretrizes e Bases da Educação Nacional (LDB), incluindo a regulamentação da modalidade EAD, cresce a cada dia o número de instituições que oferecem diferentes cursos ofertados a distância (TAKAHASHI, 2010).

Em 21 de junho de 2017, foi publicado o Decreto № 9.057/2017, que Regulamenta o art. 80 da Lei no 9.394, de 20 de dezembro de 1996, que estabelece as diretrizes e bases da educação nacional, que diz respeito justamente ao ensino EAD. De forma geral, o decreto oferece maior autonomia às IES na oferta da modalidade, visando o aumento da oferta de vagas, através da abertura de mais polos de apoio presencial pelas IES já existentes e a abertura de novos cursos, por IES que ainda não atuam com a EAD (BRASIL, 2017).

Com o crescente número de IES atuando no mercado, foi preciso também inovar na variedade dos cursos oferecidos na modalidade, e assim, cursos até então que apresentavam características de formação tão práticas, que a princípio não apontavam para o EAD, foram repensados e incluídos nesse projeto, trazendo um novo perfil não só de cursos, mas de metodologias e de alunos. Entre as inovações do EAD estão os cursos de design, que passaram a ser ofertados também à distância, em seus diferentes segmentos (BORGES \& JESUS, 2014).

\section{O ensino do design EAD e as metodologias ativas}

O modelo tradicional linear de ensino precisou ganhar novas formas com a consolidação do EAD no Brasil, já que a modalidade exige um novo papel do professor, da avaliação e do próprio ensino-aprendizagem. Ao profissional de educação cabe promover o rompimento com os paradigmas tradicionais de aprendizado.

No contexto do ensino de design, surge então, a necessidade (ou até, obrigatoriedade) de se desenvolverem técnicas, ferramentas e metodologias que proporcionem não somente a autonomia do aluno, mas que, viabilizem a realização de atividades de características mais práticas, tão comuns e importantes na formação de designers. No ensino presencial, as aulas em ateliês e a dinâmica de supervisão docente, aula a aula, parecem, e realmente não é, possível de replicação no EAD.

E desta maneira, os cursos com proposta de formação em EAD para design, precisam desenvolver formatos que viabilizem esse processo de aprendizagem. Surgem aí propostas e projetos para esse atendimento, baseadas em experiência já testadas da educação a distância em outros cursos, normalmente, de gestão e de licenciaturas, esses, já bastante comuns e espalhados 
por todo o país.

Além disso, novas ferramentas aplicadas a educação são repensadas no contexto da EAD, viabilizando, ou, ao menos, aprimorando as possibilidades da modalidade no ensino de cursos de design. Entre estas, destacamos as metodologias ativas, que visam justamente a promoção de autonomia aos alunos, tornando-se assim um importante processo no engajamento do discente dessa modalidade de ensino, considerando, especialmente, a necessidade de autogestão que o aluno tem dentro do EAD precisa, o que torna a promoção de autonomia essencial ao indivíduo que busca aprendizado.

Entendemos aqui que "[...] autonomia significa a faculdade de se governar por si mesmo; o direito ou faculdade de se reger por leis próprias; liberdade ou independência moral ou intelectual" (NERBEL, 2011, pg. 26) e, desta forma, podemos compreender a importância do desenvolvimento de autonomia no discente como fator primordial para implantação de novos modelos de aprendizagem. E neste contexto, ao utilizar as metodologias ativas o professor exerce o papel de mediador, sendo aquele que contribuirá no sentido de facilitar a implementação e prática de metodologias que possibilitam ao aluno sua autonomia e uma nova forma de aprender (BERBEL, 2011), e isso, somente fortalece a prática como bastante aplicável ao EAD, indo ao encontro com características básicas da modalidade.

Dentro das metodologias ativas de ensino destaca-se a Aprendizagem Baseada em Problemas - ABP, que segundo Borochovicius e Tortella (2014, p. 268), "tem como premissa básica o uso de problemas da vida real para estimular o desenvolvimento conceitual, procedimental e atitudinal do discente". Ainda para os autores, a ABD motiva e impulsiona os envolvidos a conhecerem melhor o seu próprio mundo, para então, utilizar essas experiências na busca de solução aos problemas apresentados.

No EAD e educador oferece propostas de problemas aos alunos e através do material didático disponibilizado, de aulas expositivas e de materiais extras, tais como textos de blogs especializados e vídeos, e os alunos buscarão formas para solucionar o problema em questão. Através dessas metodologias ativas o aluno tem a sua disposição recursos que o auxiliarão na tarefa de aprender a aprender. Considerando o ensino do design, a metodologia é tão viável e aplicada, na verdade, até além disso, podemos compreender a metodologia como uma das maneiras a viabilizar o ensino de design na metodologia EAD, inclusive, aplicada ao desenvolvimento de atividades mais práticas, necessária para a formação de designers.

\section{Experiência prática}

Para ilustrar a experiência do uso da metodologia ativa, mais especificamente, da ABP, no ensino de design utilizaremos uma atividade proposta para o curso superior de tecnologia em design de interiores, modalidade EAD, durante a disciplina de Metodologia de projeto em design. Importante ressaltar que a estrutura aplicada na instituição de ensino em questão, é baseada no sistema modular, e que em se tratando da 1a disciplina do 30 módulo do 10 ano do curso, trata-se de uma disciplina que somente alunos do 1 o ano cursam, salvo dependentes, podendo, inclusive, ser a $1^{\text {a }}$ disciplina cursada por um aluno ingressante.

Essas características fortalecem ainda mais o princípio da importância e até, necessidade, do uso de metodologias alternativas aplicadas ao caso, considerando o perfil variante de alunos, 
que podem até mesmo, não ter tido contato nenhum com outro conteúdo do curso, e, mesmo assim, para o entendimento e formação da disciplina, importante o desenvolvimento da prática. Vale ressaltar que, dentro da metodologia do curso ainda estão previstas atividades de cunho teórico, incluindo prova com questões objetivas e dissertativas.

Desta maneira, como proposta para a atividade de características práticas, o aluno, primeiramente, recebeu um texto que apresentava o conceito de família monoparental, que o contextualizou com as solicitações inseridas na sequência, que indicaram que ele deveria desenvolver as etapas de um pré-projeto de uma sala para uma família de perfil monoparental. Para tal, deveriam buscar uma família com essas características, para que o briefing fosse elaborado a partir de situações e problemas reais. Os alunos receberam uma lista de etapas que deveriam ser cumpridas, incluindo ferramentas do processo aprendidas durante as aulas da disciplina.

Assim, os alunos receberam os seguintes comandos sobre o que deveriam produzir e entregar: 1a Etapa: Coletar informações relevantes do seu cliente (Briefing). Qual o problema e os objetivos da criação deste ambiente? A que público se destina? Quem é seu cliente? História, gostos, desejos, necessidades, dificuldades etc. 2a Etapa: Elaborar um Brainstorming (Tempestade de Ideias). "Hora de viajar!" Expressa no papel tudo o que the vier à mente, com relação à solução para o espaço a ser projetado, com símbolos, figuras, palavras e quaisquer desenhos que façam você pensar melhor sobre a solução depois. 3a Etapa: Construir um Painel Semântico (físico, manual ou digital). Com referência ao briefing inicial, transmita sentidos e emoções por meio de imagens. 4a Etapa: Criar o conceito principal para o possível desenvolvimento de projeto de interiores - SALA. Qual foi a linha de raciocínio ao criar esse ambiente e qual o conceito que quer transmitir ao cliente. 5a Etapa: Escrever um Memorial Justificativo. Relacione suas escolhas e justifique-as, embasadas nas etapas anteriores (Briefing, Brainstorming, Painel Semântico e conceito de projeto).

Importante frisar que os alunos foram contextualizados com o tema "monoparental" através de leituras antes de receberem os comandos. Ao final, ainda estavam disponíveis as seguintes informações: Lembrando que este projeto não será desenvolvido, mas sim o princípio da criação deste; Os painéis poderão ser feitos com recortes, colagem, desenho e fotografias (de forma manual ou utilizando qualquer software). Na sequência, apresentaremos um dos trabalhos entregues.

Figura 1 - Resultado de um trabalho entregue

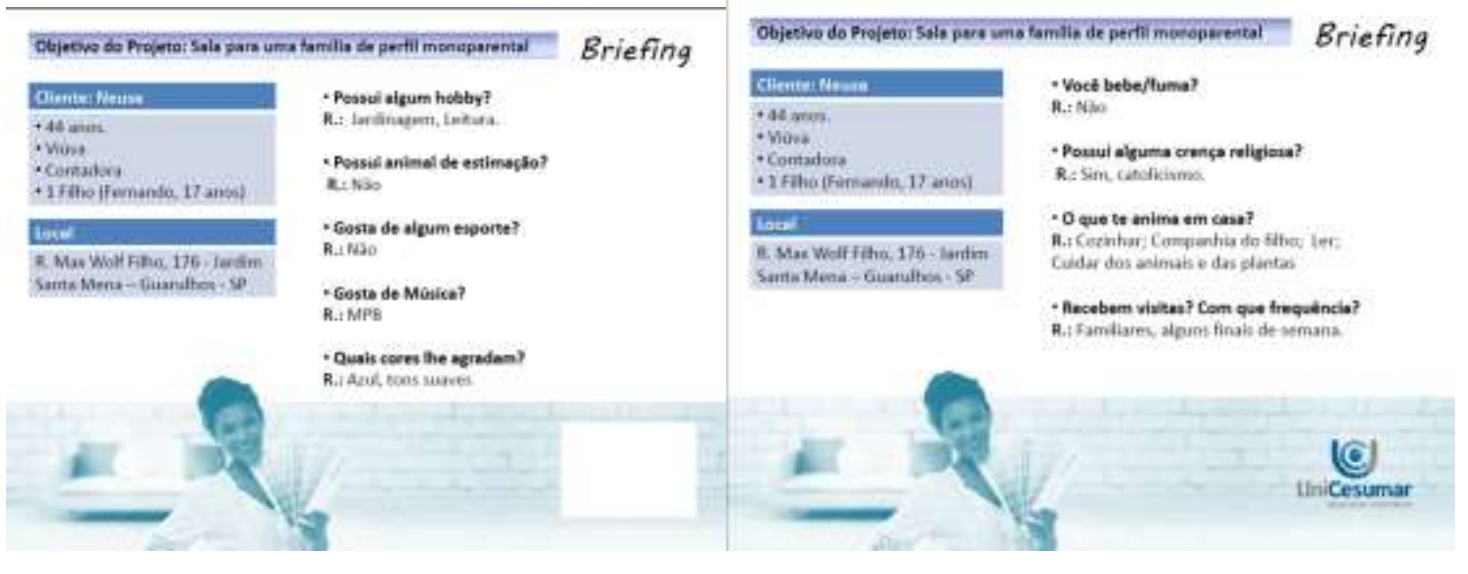




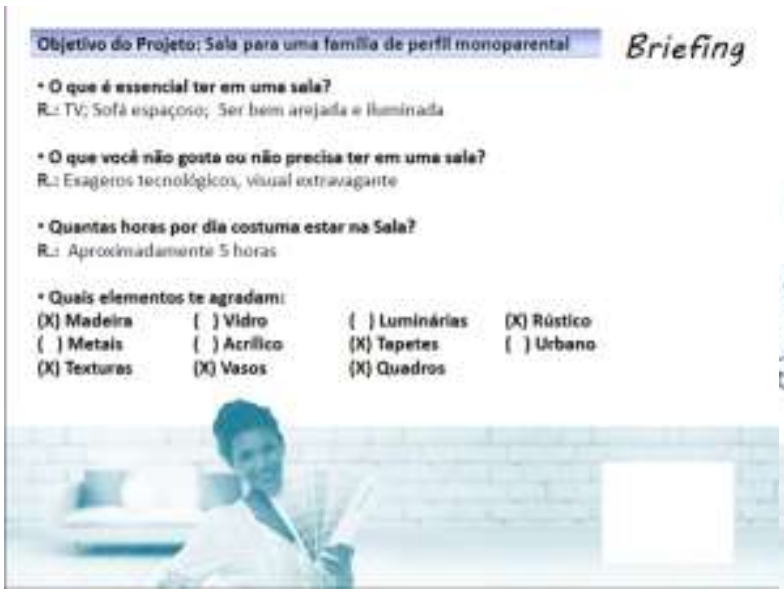

-O que deasencial ter em ume sele

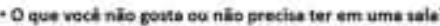

IMetais 1 jacrilico

(x) Tapeter

(x) Rüstico

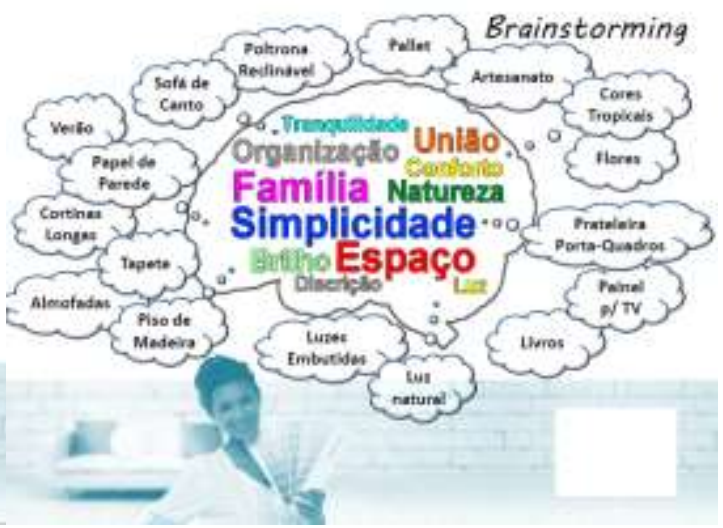

Conceito do Projeto - Sala

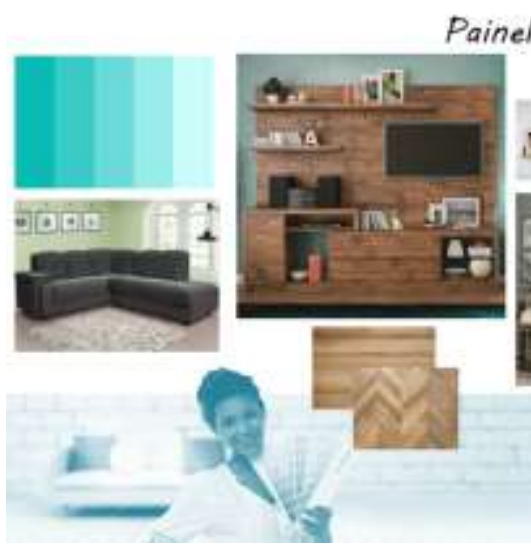

Painel Semântico

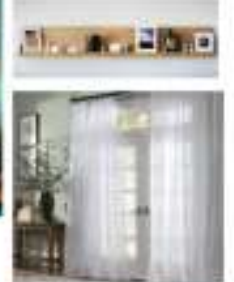

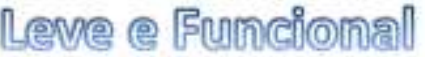

Sala com estilo campestre: Um ambiente acolhedor e que faz bom uso da luz do dia.

\section{Memorial Justificativo}

Para o desenvatidmerto do projeto de interiores, identificamos a necessidade de otimizs a sensag bo de trancuilidade no amtiente, acolhendo

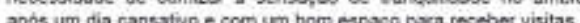

Sers usado come base os tons de azul e verde uma combinacto de cores tropicais com ouftos elementos de pores neutras ou eave remetam a natureza camo fores e objetos de madeira criando uma perteta sintonia entre a sala e o jardim, assim como on hobbies da diente

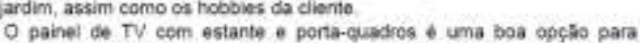
agrupar toda a interatuidade do ambiente, e juntarvente com o plso de madeira reforcam a ideia russica do orojeto, em tons opostos acs demas elemertos refortan a ideia nustica do projeto, em lans opostos acs demas elemertos crianda um destaque naturs, sem exto, o tapele e as octinas longas aumentam a sensaç5o de espasco, objetivo primordial do propeso

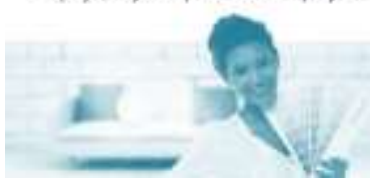

Fonte: As autoras

O exemplo apresentado ilustra a maior parte dos trabalhos entregues. Cerca de $80 \%$ dos alunos que entregaram o trabalho apresentaram todos os itens atendidos. Nem todos estes apresentavam o item atendido completamente, contemplando todos os quesitos, mas em geral, observa-se que ocorreu a compreensão da proposta. Percebeu-se que com a apresentação da 
situação problema, considerando a prática do $A B P$, o aluno, em geral, foi capaz de solucionar o caso, mesmo sem uma orientação de forma presencial, a partir dos comandos, aproveitando-se dos problemas reais, que fazem parte do cotidiano do aluno.

\section{Considerações finais}

A educação na modalidade a distância é uma realidade que visa o atendimento de diversas demandas atuais, inclusive a do próprio perfil da geração de novos estudantes universitários, pertencentes a geração Y. Neste contexto, encontramos os desafios do ensino-aprendizagem, no contexto das práticas ainda enraizadas nas didáticas tradicionalistas. Romper com os hábitos do ensino, exige que novas ferramentas sejam empregadas.

Pensando no ensino do design, se faz necessária uma disruptura ainda maior, mesmo quando imaginamos que o perfil do ensino-aprendizagem nestes cursos não segmen um modelo tão delimitado como outros cursos, para a aplicação no EAD, o "salto" parece ainda maior, caracterizando para alguns, inclusive, que essa é uma prática que dificilmente ofertará qualidade. As metodologias ativas vão ao encontro dessa atualidade, disponibilizando uma nova conjuntura, em paralelo a disruptura das antigas práticas. $O$ método $A B P$ pode e deve ser utilizado como auxiliar no ensino do design na EAD, se tornando uma grande ferramenta no contexto.

\section{Referências}

BERBEL, N. A. N. As metodologias ativas e a promoção da autonomia de estudantes. Semina: Ciências Sociais e Humanas, Londrina, v. 32, n. 1, p. 25-40, jan jun 2011. ISSN 1679-0383.

BORGES, E. M.; JESUS, D. P.. A EAD no contexto educacional: propostas para avaliação. Revista Brasileira de Aprendizagem Aberta e a Distância, v. 13, p. 193-209, 2014.

BOROCHOVICIUS, E.; TORTELLA, J. C. B. Aprendizagem Baseada em Problemas: um método de ensino-aprendizagem e suas práticas educativas. Revista Ensaio: Avaliação e Políticas Públicas em Educação, Rio de Janeiro, v. 22, n. 83, p. 263-294, 2014. ISSN 1809-4465.

BRASIL. Ministério da Educação. Instituições de Educação Superior e Cursos Cadastrados. 2017. Disponível em: <http://emec.mec.gov.br/>. Acesso em 05 de set. de 2017.

. Ministério da Educação. Parecer n. 436, 2001

LANDIM, P. C. Design, empresa, sociedade [online]. São Paulo: Editora UNESP; São Paulo: Cultura Acadêmica, 2010.

TAKAHASHI, A. R. W. Cursos superiores de tecnologia em gestão: reflexões e implicações da expansão de uma (nova) modalidade de ensino superior em administração no Brasil. RAP - Revista de Administração Pública, v.44. n.2, p. 385-414, mar/abr. 2010. 